\title{
Plantar pressure analysis after percutaneous repair of displaced intra-articular calcaneal fractures
}

\author{
Tim Schepers ${ }^{1}$, Arjan Van der Stoep ${ }^{1}$, Hans Van der Avert ${ }^{2}$, \\ Esther M.M. Van Lieshout ${ }^{1}$, Peter Patka ${ }^{1}$
}
1. Department of General Surgery, Traumatology, Erasmus MC, University Medical Center Rotterdam, the Netherlands
${ }^{2}$. Jongenengel Orthopedisch Centrum Rotterdam

Corresponding author:

T. Schepers, MD

Erasmus MC, University Medical Center Rotterdam

Department of General Surgery and Traumatology

Room Hs-303

P.O. Box 2040

3000 CA Rotterdam, The Netherlands

E-mail: t.schepers@erasmusmc.nl

Phone: +31-10-4631050

Fax: +31-10-4632396 


\section{Abstract}

Introduction: Clinical results for the treatment of displaced intra-articular calcaneal fractures are mainly expressed using disease-specific outcome scores, physical examination and radiographs. We hypothesized that plantar pressure and foot position analysis is a valuable tool in assessing foot function in patients with a unilateral displaced intra-articular calcaneal fracture treated percutaneously.

Patients and methods: With a follow-up of at least one year 21 patients with a unilateral displaced intra-articular calcaneal fracture treated percutaneously participated in the study. The pedobarographic measurements in the injured foot were compared with the contralateral control foot. Correlations between the ratios (injured/control) of plantar pressure and foot position variables and outcome scores, the physical exam items ratios, the fracture classification and the radiological parameters were calculated.

Results: Statistically significant differences between the injured and the control foot were found for the weight distribution $(p=0.002)$, total contact time $(p<0.001)$ and the maximum pressure under the first metatarsal $(p=0.02)$ after a median follow-up of 18 months. Of all correlations calculated, only the heel time ratio correlated statistically significant with the heel width ratio $(p=0.004)$. Conclusion: Significant differences in plantar pressure distribution between the injured and uninjured foot were found, indicating that plantar pressure analysis and foot position analysis is an objective test to assess deviations in foot function. Plantar pressure data revealed limited correlation with outcome scores. Therefore, plantar pressure analysis should not be used instead of but in addition to established outcome scores. 


\section{Keywords}

Calcaneus, fracture, outcome, plantar pressure and foot position analysis 


\section{Introduction}

Various modalities exist for the treatment of displaced intra-articular calcaneal fractures. Frequently applied are open reduction and internal fixation $(\mathrm{ORIF})(1)$, conservative management(1), three-point distraction according to Forgon and Zadravecz(2), percutaneous reduction according to Essex-Lopresti(3), manual reduction(4) and primary arthrodesis.(5) The percutaneous distraction technique according to Forgon and Zadravecz has been applied at our institute since 1998, with minor modification. $(2,6)$

Clinical results of treatment of displaced intra-articular calcaneal fractures have mainly been documented using disease-specific outcome scores. Infrequently, pressure distribution analyses have been used to analyze functional results after ORIF,(7-8) closed and semi-open treatment(9) and conservative treatment.(10-11) The studies comparing operative and conservative treatment showed improved results after surgical treatment.(12-14) Patients showed a better compensated walking pattern,(14) improved functional results, and reported fewer subjective complaints compared with patients treated conservatively.(12)

In determining which plantar pressure and foot position variables have been investigated earlier, the literature (Pubmed) was reviewed for previous use of plantar pressure and foot position analyses after calcaneal fractures, up to May 2007, using the following search-terms and Boolean operators: ('calcaneus' OR 'os calcis' OR 'calcaneum' OR ‘calcaneal') AND 'fracture' AND ('gait' OR 'plantar pressure'). This search identified thirteen studies; 9 used a platform as measuring device and 4 used 
insoles (Table 1). The number of items used per study ranges from 1 to 11 . In total 24 different items were analyzed, of which 7 were determined only once. The most frequently used parameters were the Centre of Pressure (COP) and the pressure under different areas of the foot, which were both determined in 8 studies.

The aim of the current study was to assess the value of plantar pressure and foot position as a measure of outcome in patients with a unilateral displaced intraarticular calcaneal fracture treated according to a percutaneous distraction technique. The second aim was to determine the clinical relevance of pedobarographic analysis by studying whether plantar pressure pattern and foot position correlated with established outcome measurements such as disease specific questionnaires, fracture classification, radiographic data and physical exam data. 


\section{Patients and methods}

\section{Patients}

Twenty-one patients (median age 51yr, percentiles 46-55; weight $80 \mathrm{~kg}$, percentiles $70-89$; height $1.71 \mathrm{~m}, 25^{\text {th }}$ to $75^{\text {th }}$ percentile $168-180 ; 67 \%$ male) with a unilateral displaced intra-articular calcaneal fracture treated by the percutaneous distraction technique according to Forgon and Zadravecz participated in this study after signing informed consent. The study was approved by the local ethical committee. These patients were a selected group from a larger cohort, after excluding patients because of migration or unknown address $(n=9)$, demise $(n=2)$, spinal cord lesion ( $n=1)$, bilateral calcaneal fractures and additional ipsi- and contralateral lower extremity fractures $(n=11)$, prior to this study.(6) The left foot was injured in 10 cases and the right in 11 . The median follow-up time was 18 months $\left(25^{\text {th }}\right.$ to $75^{\text {th }}$ percentile 16-26). Trauma mechanism was a fall from height $(n=10)$, a fall from the stairs or a ladder $(n=9)$, or a motor vehicle accident $(n=2)$. Considering the EssexLopresti(1) conventional radiographic classification there were 3 tongue type, 12 joint depression type and 6 comminuted type fractures. The Sanders $(1,15)$ CTclassification showed 9 type II, 5 type III and 5 type IV fractures. For two patients the classification could not be determined as the CT-scans were not available.

Outcome was determined using three disease-specific outcome scores, and satisfaction with overall treatment was determined using a Visual Analogue Scale (VAS; range 0-10)(16), American Orthopaedic Foot and Ankle Society Hindfoot Score (AOFAS)(17), Maryland Foot Score (MFS)(15), and Creighton-Nebraska Score $(\mathrm{CN})(18)$. 
The physical exam was conducted by one independent observer with the patient in kneeling position with the ankle and foot freely movable. The range of motion (ROM) of the ankle and subtalar joint were measured using goniometry. The heelwidth $(\mathrm{mm})$ was measured from the plantar side of the foot, at the level of both malleoli using sliding calipers. Standardized weight-bearing lateral radiographs were evaluated by one observer (TS) and an independent radiologist using goniometry; mean values were calculated from both observers. From the lateral radiograph the lateral view the angles of Böhler and Gissane were measured.

\section{Dynamic pedobarographic analysis}

All plantar pressure distribution analyses were performed at a specialized centre for foot, ankle and gait abnormalities. A plantar pressure plate (Footscan ${ }^{\circledR}$, RSscan International, dimensions $(\mathrm{L} \times \mathrm{W} \times \mathrm{H}): 2 \mathrm{~m} \times 0.4 \mathrm{~m} \times 0.02 \mathrm{~m}, 16.384$ sensors, 2 sensors per square $\mathrm{cm}, 100 \mathrm{~Hz}$ ) was embedded in a $5 \mathrm{~m}$ long walking track. Subjects were unaware of the exact position of the pressure plate within this platform. Patients were asked to walk at a free-walking velocity on this platform. The following items were determined: the weight distribution between the injured and uninjured foot while standing still, the maximum distance-change (delta $x$ ) in mediallateral direction of the centre of pressure line from the reference line $(\Delta x \operatorname{COP}$; Figure $1 \mathrm{~A}$ ) to the foot axis, total contact time, load time percentage (percentage of loading, compared with unloading, during one single step), heel time, the total contact area, the degrees of abduction relative to the walking direction, $(8,19-20)$ and the maximum pressure (Pmax) beneath the medial heel $(\mathrm{H} 1)$, lateral heel $(\mathrm{H} 2)$, metatarsals (M1 to M5) and the hallux (T1) (Figure 1B). The medial-lateral foot ratio $((\mathrm{H} 1+\mathrm{M} 1+\mathrm{M} 2) /(\mathrm{H} 2+\mathrm{M} 3+\mathrm{M} 4+\mathrm{M} 5))$ was calculated. Five recordings were made for 
each patient. The lowest and highest scores for every item were deleted, the three remaining were averaged. Two investigators (AS, EL) measured all plantar pressure and foot position variables in duplicate to determine intra-observer variability and inter-observer agreement.

\section{Statistical analysis}

The statistical analysis was performed using the Statistical Package for the Social Sciences (SPSS) version 12.0 (SPSS, Chicago, IL, USA). The KolmogorovSmirnov test was used to test for normality of the data. The Levene's test was applied to assess homogeneity of variance between data of injured and control feet. Since most items did not show normal distribution or equal variance, all items were regarded as non-parametric for the statistical analysis. Therefore median numbers and the $25^{\text {th }}$ to $75^{\text {th }}$ percentile are provided.

The intraclass correlation coefficient (ICC) was determined as an index of reliability to measure repeatability (intra-observer reliability) and reproducibility (inter-observer reliability) of the pedobarographic analysis. These were graded according to Landis and Koch (21): 0 , poor; 0.01 to 0.2 , slight; 0.21 to 0.4 , fair; 0.41 to 0.6 , moderate; 0.61 to 0.8 , substantial; and 0.81 to 1.0 , almost perfect agreement.

The Wilcoxon signed ranks test was used to assess whether plantar pressure and foot position variables differed between the injured and uninjured foot. For all items the ratio of injured versus unaffected foot was calculated. The Spearman rank test was applied to correlate these ratios to the disease-specific outcome scores, the VAS, and data from the physical exam. The radiological data and the fracture classification were correlated with the Footscan data of the injured foot. The Bonferroni correction was applied to correct for multiple comparisons; meaning that 
the significance level of $p=0.05$ was divided by the number of correlations determined. 


\section{Results}

\section{Patients}

The median AOFAS was 88 points $\left(25^{\text {th }}\right.$ to $75^{\text {th }}$ percentile $\left.82-98\right)$. For the MFS this was $89\left(25^{\text {th }}\right.$ to $75^{\text {th }}$ percentile $\left.78-94\right)$, and the $C N$ was $83\left(25^{\text {th }}\right.$ to $75^{\text {th }}$ percentile $73-$ 94). The median VAS score was $8\left(25^{\text {th }}\right.$ to $75^{\text {th }}$ percentile $\left.7-9\right)$. Determined from the physical exam the median ratio (injured/uninjured) of the ROM of the ankle joint in sagittal direction was $0.90\left(25^{\text {th }}\right.$ to $75^{\text {th }}$ percentile $\left.0.82-1.00\right)$ and the median ratio of the subtalar joint in the in- and eversion plane was $0.76\left(25^{\text {th }}\right.$ to $75^{\text {th }}$ percentile 0.50 0.92). The median ratio for the heelwidth was $1.06\left(25^{\text {th }}\right.$ to $75^{\text {th }}$ percentile $\left.1.03-1.09\right)$. The median ratio of Böhlers angle of the injured foot at follow up versus that of the control foot was $0.57\left(25^{\text {th }}\right.$ to $75^{\text {th }}$ percentile $\left.0.30-0.82\right)$, for the Gissanes angle this was $1.04\left(25^{\text {th }}\right.$ to $75^{\text {th }}$ percentile $\left.0.99-1.08\right)$.

\section{Pedobarographic analysis}

The results of the plantar pressure and foot position variables analysis are shown in Table 2. Patients generally put more weight on the control foot than on the injured foot while standing. The injured foot had a statistically significantly reduced total contact time and higher maximum pressure under the first metatarsal compared with the control foot. None of the other items analyzed showed statistical difference between both feet.

To determine the accuracy of the measurements, the repeatability and the reproducibility were determined for all plantar pressure and foot position variables. The intra-observer reliability ranged from $0.83-1.00$ for the first observer (AS) and 
from $0.96-1.00$ for the second observer (EL). The inter-observer reliability ranged from 0.95-1.00.

To determine whether plantar pressure and foot position variables associated with clinical and outcome parameters, all pedobarographic pattern items were correlated with outcome scores, physical exam data and radiological data. Although several trends were observed, only the association between heel time (ratio injured/control) and heel width (ratio injured/control) were statistically significant after applying the Bonferroni correction: $\left(R_{s}=0.60, p=0.004\right)$. The correlations with the outcome scores and VAS are shown in Table 3. None of the plantar pressure and foot position variables correlated statistically significant with commonly used outcome scores. However, there were trends for an inverse correlation of the percent load time with the VAS $\left(R_{s}=-0.47, p<0.03\right)$.

Although not statistically significant upon Bonferroni correction, the heel time ratio tended to associate with the $R O M$ ratio in the sagittal plane $\left(R_{s}=0.49, p=0.02\right)$. 


\section{Discussion}

The current study was conducted to establish pedobarographic deviations after percutaneous repair of displaced intra-articular calcaneal fractures and to correlate these data with standardized questionnaires, physical exam and radiographs. Data revealed changes in foot form and in the physiology of walking after an intraarticular calcaneal fracture. This is in concordance with findings from other studies. $(9,11,13-14,20,22)$ Since treatment modalities, dynamic pressure and footscan equipment, items analyzed, and outcome scoring systems applied vary between studies, extrapolating data from one study to another is difficult.

At our institution the percutaneous technique was used as sole treatment for intraarticular calcaneal fractures. Only patients with a unilateral intra-articular calcaneal fracture treated percutaneously were included, justifying the use of the contra lateral foot as internal control.

Of all items used by others, the COP has been applied most. Four out of 8 studies reported a lateral shift of the COP line after calcaneal fracture.(8, 14, 22-23) However, as it was frequently not specified how this was calculated, subjectivity cannot be ruled out. In the current study a reproducible and quantitative method was chosen to determine the Max $\Delta x$ COP. This method revealed no statistically significant difference between the injured and control foot, indicating equal stability of both feet; in contrast to the study by Davies et al, who measured only the lateral deviation from the reference line.(23) An explanation for this difference might be the good subtalar movements in this study, which has shown correlation with 
lateralization of the centre of pressure line. $(20,23) \mathrm{A}$ load shift to the lateral side for the injured foot reflecting reduced mobility of the subtalar joint was suggested in three studies. $(8,20,22)$ The higher Pmax under M1 of the injured side as found in our study, however, suggests a medial rather than a lateral shift. Analyzing the Pmax ratio of medial/lateral areas revealed a trend towards lateralization of the injured foot; however this difference was not statistically significant because of the low power. In the study by Rosenbaum the lateral load shift was visualized by a significant increase in peak pressure at the level of the $5^{\text {th }}$ metatarsal and a decrease under the head of the first metatarsal. This lateralization was not seen in other areas of the foot.(20) In their study only fourteen patients were included, of which two-third was treated operatively and one-third conservatively.

The current study indicated that patients bear weight on their injured foot significantly less while standing, and put more pressure on the first metatarsal of the injured foot than on the contralateral uninjured side. Since the heel time of the injured foot equals that of the control foot, these data imply that patients avoid walking on the injured heel. This could either be the consequence of existing physical complaints, or because of fear of physical complaints. This finding is in agreement with that of Rosenbaum.(20) As opposed to our study, Follak and Merk showed a trend in increased loading of the injured foot during standing, due to a greater loading of the forefoot.(9) It cannot be ruled out that this difference might be attributed to a difference in follow up time between their study (5 years) and the current study (1.5 year). Unfortunately the current study has insufficient power to assess if a correlation with follow up time exists. Moreover, Follak included patients 
treated with closed $(n=15)$ and semi-open $(n=15)$ repositioning of fragments, whereas in our study all patients are treated with the same treatment modality.

In our population the total contact time was statistically significantly shorter for the injured foot compared with the control foot. As the power for this item was low $(17 \%)$, the meaning of this finding might be questioned. Increased contact phases were found by Siegmeth et al.(12) and Toth et al.(13), who also used pressure plates in their studies. The latter group reported a statistically significantly increased contact time of the injured midfoot. As opposed to these findings, studies by Follak(9) and Kinner(8) revealed equal total contact times and stance phase for both the injured and the control foot. In these two studies insoles were used instead of pressure plates. The interpretation of these results is complicated by a large variety in patient numbers (range 20-171) and follow up time (24-72 months).

Of all correlations calculated, only heel time ratio correlated statistically significantly with heel width ratio. Other trends were identified, but lost statistical significance after correction for multiple testing. This means that pedobarographic analysis cannot be used as a replacement of routinely performed tests. The near perfect reproducibility and repeatability of our analyses indicate the high accuracy of the plantar pressure analyses performed. Therefore, determining plantar pressure and foot position variables may be a valuable addition to the panel of tests and outcome scores to assess differences between the injured and uninjured feet.(8-9)

It cannot be ruled out that for some items analyzed a limited power might have compromised the study results. A sample size of 325 patients would be required in 
order to reach sufficient power for all items (data not shown). Due to the low incidence of unilateral displaced intra-articular fractures and the strict inclusion criteria chosen this is not feasible.

Dynamic pedobarography and gait analysis are objective measurements of foot function after intra-articular calcaneal fractures $(8,19,23)$ and have been shown to correlate inconsistently with different outcome scoring systems, radiological parameters and physical exam. $(19,23-24)$ It is said to be superior to radiographic analysis in assessing functional outcome(19), and will find increasing use in the evaluation and assessment of musculoskeletal function after reconstructive or corrective surgery.(9) The near perfect reproducibility and repeatability indicate the high accuracy of the pedobarographic analyses as described here supports the latter. This implies that, although correlation with outcome or radiology is poor, pedobarographic pattern analysis represents a reliable addition to the panel of tests and analyses performed at present. 


\section{Conclusion}

Treatment of displaced intra-articular calcaneal fractures percutaneously according to Forgon and Zadravecz yields satisfying results on average. Patients had high scores on the different outcome scores and there were few statistically significant differences between the injured and the control foot during walking on plantar pressure and foot position variables.

Most of the plantar pressure and foot position variables analyzed did not correlate with the disease-specific questionnaires, physical exam and standardized radiographs, rendering the place of pedobarographic analysis in determining outcome after a displaced intra-articular calcaneal fracture unclear.

Pedobarography may represent a valuable addition to the currently applied tests such as radiographic and physical exams to assess the functional recovery status as shown in the literature, but large variation exists in methods and measured parameters. More uniformity is required to compare results of different studies and treatments, thus enhancing insight in a most disabling injury. 


\section{References}

1. Buckley R, Tough S, McCormack R, Pate G, Leighton R, Petrie D, et al. Operative compared with nonoperative treatment of displaced intra-articular calcaneal fractures: a prospective, randomized, controlled multicenter trial. J Bone Joint Surg Am. 2002 Oct;84A(10):1733-44.

2. Forgon M. Closed reduction and percutaneous osteosynthesis: Technique and results in 265 calcaneal fractures. In: Tscherne H, Schatzker J, eds Major fractures of the pilon, the talus, and the calcaneus New York: Springer-Verlag. 1993:207-13.

3. Essex-Lopresti P. Mechanism, reduction technique and results in fractures of os calcis. Br J Surg. 1952;39:395-419.

4. Omoto H, Sakurada K, Sugi M, Nakamura K. A new method of manual reduction for intra-articular fracture of the calcaneus. Clin Orthop. 1983 Jul-Aug(177):104-11.

5. Buch BD, Myerson MS, Miller SD. Primary subtalar arthrodesis for the treatment of comminuted calcaneal fractures. Foot Ankle Int. 1996 Feb;17(2):61-70.

6. Schepers T, Schipper IB, Vogels LM, Ginai AZ, Mulder PGM, Heetveld MJ, et al. Percutaneous treatment of displaced intra-articular calcaneal fractures. J Orthop Sci. 2007 Jan;12(1):22-7.

7. Dudkiewicz I, Levi R, Blankstein A, Chechick A, Salai M. Dynamic footprints: adjuvant method for postoperative assessment of patients after calcaneal fractures. Isr Med Assoc J. 2002 May;4(5):349-52.

8. Kinner BJ, Best R, Falk K, Thon KP. Is there a reliable outcome measurement for displaced intra-articular calcaneal fractures? J Trauma. 2002 Dec;53(6):1094-101; discussion 102.

9. Follak N, Merk M. The benefit of gait analysis in functional diagnostics in the rehabilitation in patients after operative treatment of calcaneal fractures. Foot Ankle Surg. 2003;9:209-14.

10. Bozkurt M, Kentel BB, Yavuzer G, Ocguder A, Heycan C, Tonuk E. Functional evaluation of intraarticular severely comminuted fractures of the calcaneus with gait analysis. J Foot Ankle Surg. 2004 Nov-Dec;43(6):374-9.

11. Kitaoka HB, Schaap EJ, Chao EY, An KN. Displaced intra-articular fractures of the calcaneus treated non-operatively. Clinical results and analysis of motion and groundreaction and temporal forces. J Bone Joint Surg Am. 1994 Oct;76(10):1531-40.

12. Siegmeth A, Petje G, Mittlmeier T, Vecsei V. [Gait analysis after intra-articular calcaneus fractures]. Unfallchirurg. 1996 Jan;99(1):52-8.

13. Toth K, Boda K, Kellermann P, Zadravecz G, Korcsmar J. Clinical and gait analysis of 171 unilateral calcaneal fractures. Clin Biomech (Bristol, Avon). 1997 Apr;12(3):S17-S8. 14. Catani F, Benedetti MG, Simoncini L, Leardini A, Giannini S. Analysis of function after intra-articular fracture of the os calcis. Foot Ankle Int. 1999 Jul;20(7):417-21.

15. Sanders R, Fortin P, DiPasquale T, Walling A. Operative treatment in 120 displaced intraarticular calcaneal fractures. Results using a prognostic computed tomography scan classification. Clin Orthop. 1993 May(290):87-95.

16. Hildebrand KA, Buckley RE, Mohtadi NG, Faris P. Functional outcome measures after displaced intra-articular calcaneal fractures. J Bone Joint Surg Br. 1996 Jan;78(1):11923.

17. Kitaoka HB, Alexander IJ, Adelaar RS, Nunley JA, Myerson MS, Sanders M. Clinical rating systems for the ankle-hindfoot, midfoot, hallux, and lesser toes. Foot Ankle Int. 1994 Jul;15(7):349-53. 
18. Crosby LA, Fitzgibbons T. Computerized tomography scanning of acute intraarticular fractures of the calcaneus. A new classification system. J Bone Joint Surg Am. 1990 Jul;72(6):852-9.

19. Mittlmeier T, Morlock MM, Hertlein H, Fassler M, Mutschler W, Bauer G, et al. Analysis of morphology and gait function after intraarticular calcaneal fracture. J Orthop Trauma. 1993;7(4):303-10.

20. Rosenbaum D, Lubke B, Bauer G, Claes L. Long-term effects of hindfoot fractures evaluated by means of plantar pressure analyses. Clin Biomech (Bristol, Avon). 1995 Oct;10(7):345-51.

21. Landis JR, Koch GG. The measurement of observer agreement for categorical data. Biometrics. 1977 Mar;33(1):159-74.

22. Mittlmeier T, Morlock MM, Kollmitzer J, Zwick EB, Lob GC. Efficiency of gait measurement after complex foot trauma. Foot and Ankle Surgery. 1996;2:197-208.

23. Davies MB, Betts RP, Scott IR. Optical plantar pressure analysis following internal fixation for displaced intra-articular os calcis fractures. Foot Ankle Int. 2003 Nov;24(11):851-6.

24. Toth K, Fabula J. Follow-up pedobarographic study of calcaneus fractured patients Gait and posture. 1994;2(4):247.

25. Contreras MEK, Muniz AMS, Souza JB, Aliva AOV, Borges NG, Barbosa DRF, et al. Biomechanical evaluation of intra articular calcaneal fracture and clinical radiographic correlation. Acta Orthop Bras. 2004;12(2):105-12. 


\section{Legend}

Figure 1: Graphical representation of pedobarographic analysis method.

A: Graphical representation of measurement method of the delta $\times$ COP, which is the maximum distance-change in medial and lateral direction during one single step of the centre of pressure line (dotted line), from the reference line that runs from the centre of the heel towards the second metatarsal head (straight line). The ratio of changes in the delta $x$ of the injured / uninjured foot was calculated.

B: $\quad$ The different areas under the medial heel $(\mathrm{H} 1)$, lateral heel $(\mathrm{H} 2)$, metatarsals (M1 to M5) and the hallux (T1) where maximum pressure (Pmax) was measured.
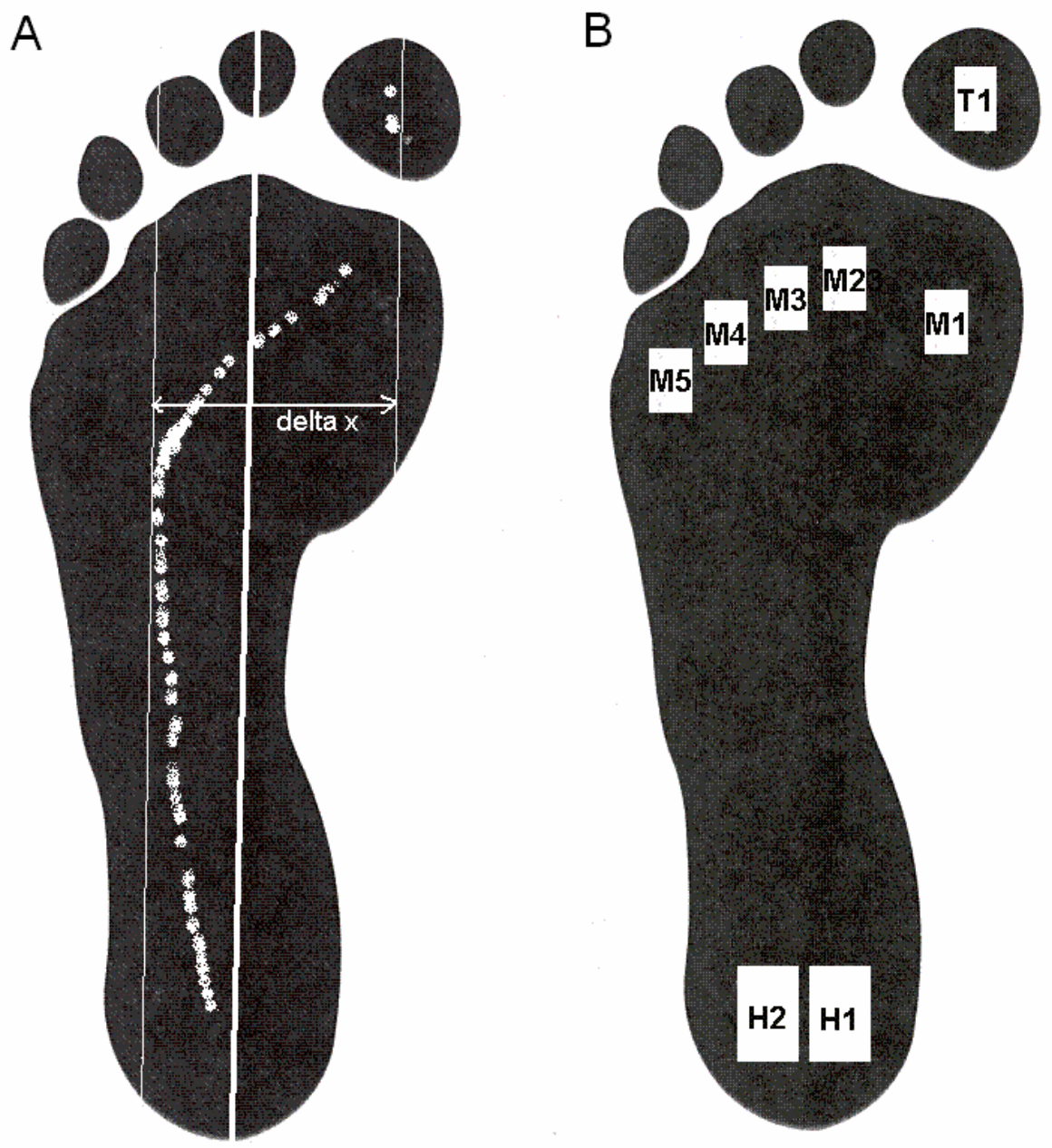
Table 1 Overview of plantar pressure and foot position items used in the literature

\begin{tabular}{|c|c|c|c|c|c|c|c|c|c|c|c|c|c|c|c|}
\hline \multicolumn{2}{|c|}{ Articles $\rightarrow$} & \multirow{2}{*}{ 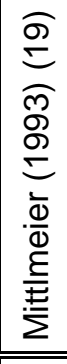 } & & \multirow{2}{*}{ 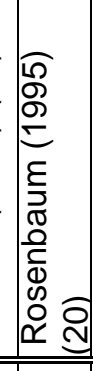 } & \multirow{2}{*}{ 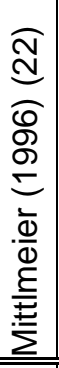 } & \multirow{2}{*}{ 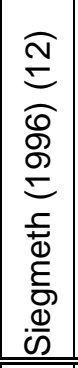 } & \multirow{2}{*}{ 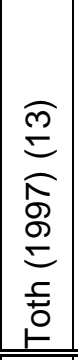 } & \multirow{2}{*}{ 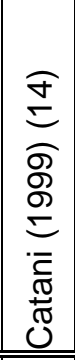 } & \multirow{2}{*}{ 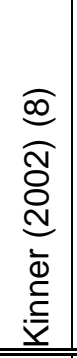 } & \multirow{2}{*}{ 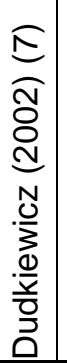 } & \multirow{2}{*}{ 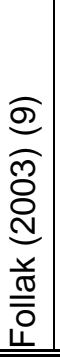 } & \multirow{2}{*}{ 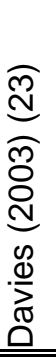 } & \multirow{2}{*}{ 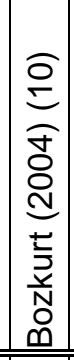 } & \multirow{2}{*}{ 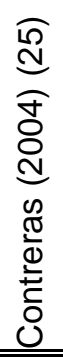 } & \multirow{2}{*}{ 흥 } \\
\hline & Parameters $\downarrow$ & & & & & & & & & & & & & & \\
\hline \multirow{5}{*}{$\begin{array}{l}\bar{\pi} \\
\overline{\frac{\pi}{0}} \\
\overline{0} \\
0\end{array}$} & platform (P) or insoles (S) & $\mathrm{P}$ & $\mathrm{P}$ & $\mathrm{P}$ & $\mathrm{P}$ & $P$ & $P$ & $\mathrm{P}$ & $S$ & $\mathrm{~S}$ & $S$ & $P$ & $\mathrm{P}$ & $S$ & \\
\hline & number of patients & 45 & 16 & 14 & 12 & 20 & 171 & 14 & 20 & 22 & 30 & 12 & 21 & 22 & \\
\hline & treatment & $\mathrm{O}$ & $\mathrm{C}$ & M & $\mathrm{M}$ & $\mathrm{M}$ & $\mathrm{M}$ & $\mathrm{M}$ & $\mathrm{O}$ & $\mathrm{M}$ & M & 0 & $\mathrm{C}$ & 0 & \\
\hline & follow-up (months) & 23 & 72 & 48 & $?$ & 59 & 50 & 18 & 24 & 60 & 62 & 45 & 38 & $>15$ & \\
\hline & Healthy controls & $\mathrm{N}$ & $\mathrm{Y}$ & $\mathrm{Y}$ & $\mathrm{Y}$ & $\mathrm{Y}$ & $\mathrm{N}$ & $\mathrm{Y}$ & $\mathrm{N}$ & $\mathrm{N}$ & $\mathrm{N}$ & $\mathrm{N}$ & $\mathrm{N}$ & $\mathrm{N}$ & \\
\hline \multirow{15}{*}{ 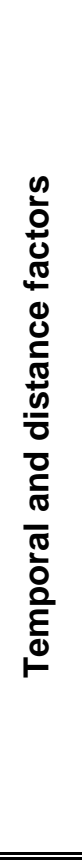 } & heel width & & & & & & & & + & & & + & & & 2 \\
\hline & mid-foot width & & & & & & & & + & & & & & & 1 \\
\hline & effective foot length & & & & & & & & & & + & & & & 1 \\
\hline & cadence (strides/min.) & & + & & + & & & & & & & & & & 2 \\
\hline & velocity $(\mathrm{m} / \mathrm{min})$ & + & + & + & + & & & + & & & & & & & 5 \\
\hline & step/stride length & + & + & + & + & & & + & & & & & & & 5 \\
\hline & $\%$ single-limb support & & + & & & & & & & & & & & & 1 \\
\hline & $\%$ double-limb support & & + & & + & & & & & & & & & & 2 \\
\hline & time of heel/initial contact & + & + & & & & & & + & & & + & & & 4 \\
\hline & time of fore-foot contact & + & + & & & & & & + & & & & & & 3 \\
\hline & stance-phase/complete contact & & + & + & & & & & + & & + & & & & 4 \\
\hline & time of contact other areas & + & & + & & + & + & & & & & & & & 4 \\
\hline & time of final contact & & + & & & & & & & & & & & & 1 \\
\hline & time to peak pressures/forces & & + & & & & & & & & & & & & 1 \\
\hline & contact area & & & + & & & & & & & & & & + & 2 \\
\hline \multirow{10}{*}{ 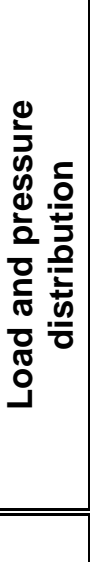 } & total sole load & & & + & & & & & & & + & & & & 2 \\
\hline & foot-ground reaction forces $\left(^{*}\right)$ & & + & & & & & + & & & & + & + & & 4 \\
\hline & maximum heel impact force & & & & & & + & & + & & & & & & 2 \\
\hline & max. fore-foot impact force & & & & & & & & + & & & & & & 1 \\
\hline & average overlap integral & & & & & & & & & & + & & & & 1 \\
\hline & pressure in different sub-areas & + & & + & & + & + & & & + & + & + & & + & 8 \\
\hline & centre of pressure line (COP) & + & & & + & + & & + & + & + & & + & & + & 8 \\
\hline & zones of max. impact & & & & & & + & & + & & & & & & 2 \\
\hline & vertical impulse difference & + & & + & + & + & & & & & & & & & 4 \\
\hline & Total number of parameters & 8 & 11 & 8 & 6 & 4 & 4 & 4 & 9 & 2 & 5 & 5 & 1 & 3 & \\
\hline
\end{tabular}

$\left(^{*}\right)$ in different directions: vertical, medial-lateral and fore-aft measured by a force plate. Treatment: $\mathrm{C}=$ conservative, $\mathrm{O}=$ operative, $\mathrm{M}=$ mixed 
Table 2 Plantar pressure data for the injured and the control foot

\begin{tabular}{|c|c|c|c|c|c|c|}
\hline & \multicolumn{2}{|r|}{ Injured } & \multicolumn{2}{|r|}{ Control } & \multirow[b]{2}{*}{$\mathrm{p}$ Value } \\
\hline & & $\overline{\text { Median }}$ & $25-75 \%$ & Median & $25-75 \%$ & \\
\hline Static & Weight distribution (\%) & 45.0 & {$[39.1-50.0]$} & 55.0 & {$[50.0-61.0]$} & $0.002^{*}$ \\
\hline Dynamic & $\operatorname{Max} \Delta x \operatorname{COP}(\mathrm{mm})$ & 41.0 & {$[31.5-50.1]$} & 38.8 & {$[27.2-46.7]$} & 0.13 \\
\hline \multirow{4}{*}{$\begin{array}{c}\text { Dynamic } \\
\text { Force }\end{array}$} & Total contact time (msec) & 791 & {$[719-861]$} & 853 & {$[752-900]$} & $<0.001^{*}$ \\
\hline & Load time (\%) & 65.6 & [42.4 - 74.9] & 61.5 & {$[47.7-74.9]$} & 0.66 \\
\hline & Heel time (msec) & 520 & [419-608] & 543 & [443-621] & 0.08 \\
\hline & Contact surface $(\mathrm{cm} 2)$ & 123.0 & [109.6 - 130.8] & 119.5 & [104.4-127.9] & 0.41 \\
\hline \multirow{10}{*}{$\begin{array}{l}\text { Dynamic } \\
\text { Pressure }\end{array}$} & $\mathrm{Pmax} \mathrm{H} 1(\mathrm{~N} / \mathrm{cm} 2)$ & 22.7 & {$[20.1-28.8]$} & 22.0 & {$[20.1-28.8]$} & 0.26 \\
\hline & Pmax H2 (N/cm2) & 21.5 & {$[17.1-29.4]$} & 23.5 & [20.1 - 29.5] & 0.16 \\
\hline & Pmax M1 (N/cm2) & 17.3 & {$[11.9-21.3]$} & 16.4 & [13.2 - 27.2] & $0.02^{*}$ \\
\hline & Pmax M2 (N/cm2) & 28.1 & {$[21.8-36.7]$} & 28.0 & [22.4 - 36.9] & 0.82 \\
\hline & Pmax M3 (N/cm2) & 28.5 & {$[19.3-34.7]$} & 25.6 & [21.7 - 37.0] & 0.43 \\
\hline & Pmax M4 (N/cm2) & 20.7 & {$[14.0-24.7]$} & 20.0 & [15.5 - 23.9] & 0.88 \\
\hline & Pmax M5 (N/cm2) & 15.2 & [9.3 - 24.8] & 14.1 & [11.1 - 19.2] & 0.32 \\
\hline & Pmax T1 (N/cm2) & 13.0 & {$[5.8-24.4]$} & 19.9 & [11.4 - 27.4] & 0.29 \\
\hline & Medial/lateral ${ }^{1}$ & 0.9 & {$[0.8-0.9]$} & 0.8 & {$[0.7-1.0]$} & 0.59 \\
\hline & Degrees of abduction & 8.1 & [3.1 - 13.8] & 11.4 & [7.2 - 15.3] & 0.15 \\
\hline
\end{tabular}

Data are given as median with the $25^{\text {th }}$ to $75^{\text {th }}$ percentile.

* significant at the 0.05 level (2-tailed; Wilcoxon Signed Rank test).

${ }^{1}$ Medial/lateral ratio calculated as $((\mathrm{H} 1+\mathrm{M} 1+\mathrm{M} 2) /(\mathrm{H} 2+\mathrm{M} 3+\mathrm{M} 4+\mathrm{M} 5))$ as described in material and methods. Max. $\Delta x \mathrm{COP}$, maximum deviation of the centre of pressure line; Pmax, maximum pressure beneath a specific area beneath the foot.

Table 3 Correlation of Footscan data with the disease-specific outcome scores and VAS

\begin{tabular}{|c|c|c|c|c|c|}
\hline & & MFS & CN & AOFAS & VAS \\
\hline Static & Weight distribution (\%) & -0.06 & 0.18 & -0.03 & -0.01 \\
\hline Dynamic & $\operatorname{Max} . \triangle \mathrm{x}$ COP $(\mathrm{mm})$ & -0.20 & 0.02 & -0.13 & 0.05 \\
\hline \multirow{4}{*}{$\begin{array}{c}\text { Dynamic } \\
\text { Force }\end{array}$} & Total contact time (msec) & 0.23 & 0.39 & 0.23 & 0.16 \\
\hline & Load time (\%) & -0.18 & -0.39 & -0.39 & -0.47 \\
\hline & Heel time (msec) & -0.07 & 0.04 & -0.03 & 0.07 \\
\hline & Contact surface (cm2) & -0.08 & 0.08 & 0.06 & -0.10 \\
\hline & $\mathrm{Pmax} \mathrm{H} 1(\mathrm{~N} / \mathrm{cm} 2)$ & -0.04 & 0.00 & 0.05 & -0.24 \\
\hline & Pmax H2 (N/cm2) & 0.05 & 0.15 & 0.06 & 0.19 \\
\hline & Pmax M1 (N/cm2) & 0.01 & 0.06 & -0.16 & -0.23 \\
\hline & Pmax M2 (N/cm2) & 0.20 & 0.18 & 0.09 & -0.14 \\
\hline Dynamic & Pmax M3 (N/cm2) & 0.27 & 0.29 & 0.17 & 0.14 \\
\hline Pressure & Pmax M4 (N/cm2) & 0.28 & 0.41 & 0.42 & 0.49 \\
\hline & Pmax M5 (N/cm2) & -0.06 & 0.14 & 0.11 & 0.25 \\
\hline & Pmax T1 (N/cm2) & 0.38 & 0.52 & 0.41 & 0.35 \\
\hline & Medial/lateral ${ }^{1}$ & -0.06 & -0.14 & -0.18 & -0.43 \\
\hline & Degrees of abduction & -0.09 & 0.11 & 0.14 & 0.12 \\
\hline
\end{tabular}


Correlation coefficients as determined using the Spearman Rank Correlation are given.

Max. $\Delta x$ COP, maximum deviation of the centre of pressure line; Pmax, maximum pressure under a specific area of the foot; MFS, Maryland Foot Score; CN,

Creighton-Nebraska Score; AOFAS, American Orthopaedic Foot and Ankle Society Hindfoot Score; VAS, Visual Analogue Score.

${ }^{1}$ Medial/lateral ratio calculated as $((\mathrm{H} 1+\mathrm{M} 1+\mathrm{M} 2) /(\mathrm{H} 2+\mathrm{M} 3+\mathrm{M} 4+\mathrm{M} 5))$ as described in material and methods.

P-values $<0.0125$ (Bonferroni correction) are considered statistically significant. 